\title{
Prediction of Construction Project Duration and Cost using Earned Value Management
}

\author{
Velumani P, Nampoothiri N, Aparnadevi R
}

\begin{abstract}
Forecasting construction project duration for future with accurate efficiency by considering all the delay factors is a big deal. Various examinations have been done to evaluate the reasons for duration delays in a construction site. Most common similarity between many factors are flawed design, inadequate supervision in workplace, shortage of supplies, absence of teamwork and local climatic conditions, causes a myriad of issues. Here, for forecasting, we chose the construction of ROB project at Kurnool, Andhra Pradesh. Though many techniques have been implemented to solve out this problem, predicting completion of an ongoing project is a big deal. Various tools have been used such as earned value management, exponential smoothing technique. After applying these techniques, a comparison with a minimal percentage of error is made and the best tool for prediction is selected. This investigation prescribes Smoothing techniques, the results become better when compared with different procedures.
\end{abstract}

Keywords: Forecasting, Exponential Smoothing techniques, Earned Value Management

\section{INTRODUCTION}

$\mathrm{P}$ duration. Generally, any project progress is a comparison between planned and actual performance and the difference is analyzed and the final duration and budget are predicted (B.C. Kim, 2010). The universally accepted method for accomplishing any project prediction is earned value management (Vanhoucke, 2015). Earned value management is an approach generally used to estimate and convey the gradual improvement of an ongoing project and to merge the three critical components of project management (capacity, duration, and estimation). It is taken into consideration that the amount of work to be completed, involves the duration and estimation that incurred to finish the work. It aids to assess and control the risk involved in the project by continual monitoring of the ongoing task with the planned task to bring out the improvement of the project (Anbari, 2003). It also indicates early signs of changes in the project which depends on each of the task execution and feasible requirement for the changes in the ongoing project (Fleming $\mathrm{Q}, 2000)$. Though earned value management brings out the schedule performance index (SPI) and schedule variance (SV) to estimate each task of the projected growth. The earned value management depends greater in schedule and

Revised Manuscript Received on December 5, 2019

* Correspondence Author

Velumani P*, Civil department, Kalasalingam Academy of Research and Education, Krishnankoil, India Email: velumani7@gmail.com

Nampoothiri N, Civil department, Kalasalingam Academy of Research and Education, Krishnankoil, India Email: drnvnnn@gmail.com

Aparnadevi , Civil department, Kalasalingam Academy of Research and Education, Krishnankoil Email: sweetyaparna95@gmail.com

cost variance (Fleming Q K. J., 2003). Furthermore, clearly, the schedule performance index and schedule variance convey that the project is either behind schedule or ahead of schedule. Also vice versa for the cost performance index and cost variance, it follows either over budget or under budget (Christensen, 1993). These performances involve some flaws in schedule variance such as inadequacy but can forecast the cost variance accurately (Yu, 2018). Also, it mainly focuses on cost management more than duration forecasting and the outcomes have less possibility to predict the project values ( $\mathrm{S}$. Vandevoorde, 2006). After all, recent analysis shows that an increase of interest in controlling the schedule performance of a project also. In addition to that, EVM is also used to forecast the entire duration of the project completion (Abdi, 2016). Also, it monitors the ongoing project structure and compared with the planned progress and to predict the completion and current project progress with the major key parameters planned value, actual value and earned value to estimate the final budget at completion ((PMI)). With the above three parameters, we can evaluate the cost performance index (CPI) and schedule performance index (SPI) based on the basic principle the past execution is the good indicator of future execution. When the future performance is like the past one, the estimate at completion (EAC) is calculated (Reinschmidt, 2010). This research focuses on a continual project analyzing and monitoring and here it leads to failure due to time overrun and errors (Rispoli, 2014).

\section{RESEARCH METHODOLOGY}

The project chosen for the EVM technique was Construction of ROB at railway $\mathrm{km} 249 / 9$ to $247 / 0$ of Secunderabad- Dhone Section in lieu of LC NO: 135E in km 359/2-4 of Chittoor-Kurnool Road, NH-18 (Within City Limits of Kurnool City). In the division of R\&B, Kurnool district in the year 2017. These projects were further categorized into Viaduct The original estimate amount of the project Rs. 3500.00 Lakhs and revised estimate amount of the project Rs. 2800.00 Lakhs.

\section{EARNED VALUE MANAGEMENT}

EVM is a method which is completely used for evaluating the schedule and cost performance of any current project and combining it with the projected cost and duration. It is a dynamic tool, where it can be compared with the actual progress and planned progress, tracking the alterations from the project baseline and to predict the outcome (duration and cost) based on the actual progress of the 
project((PMI)). EVM is the most important technique used in monitoring the progress of the project of an ongoing project.

There are three major key factors involved in this technique are planned value (PV), actual value (AV) and earned value $(\mathrm{EV})$. The above terms are used to analyze where the project goes and where the project must be (Reinschmidt, 2010). The PV line depicts the planned cost while the confirmed contractor's bid which is planned before the start of the work. In the meantime, the $\mathrm{AC}$ line depicts the total amount spent on each work and finally, the EV curve represents the actual amount received for the task done as per the planned one. $\mathrm{EV}=\mathrm{PV} X \mathrm{PC}$ (percentage of complete), it is used to represent how efficiently the resources are used. In the project after finding, the dynamical project progress is monitored and represented graphically by the values of AC and PV (Abdi, 2016). With the key parameters, SPI and CPI are found by (cost performance index) $\mathrm{CPI}=\mathrm{EV} / \mathrm{AC}$, which expresses how effectively resources are spent for the project and (schedule performance index) SPI=EV/PV, which expresses the amount of duration spent. With all the above furnishing project duration and estimate status, further, the completion time and cost can be predicted accurately (Marco, 2013). (B.C. Kim, 2010) depicts estimate at completion can be derived by depending on the EV data. At the point when the future performance is like the past performance along with time ' $\mathrm{t}$ ' $\mathrm{EAC}(\mathrm{t})$ is determined as:

\section{$\mathrm{EAC}(\mathrm{t})=\mathrm{BAC} / \mathrm{CPI}(\mathrm{t})$}

where $\mathrm{BAC}=$ Budget at the completion

\section{$\mathrm{CPI}(\mathrm{t})=$ Cost Performance index at time $\mathrm{t}$}

Despite considering all the common theory of EVM, the duration and estimate can be predicted through the schedule performance accuracy is questioned by analysts ( $\mathrm{S}$. Vandevoorde, 2006) and (Short, 1993). The major two essential properties which affect earned value management are first, schedule variance of any project is analyzed, validated and forecasted in units of value instead of time. Secondly, using schedule variance to predict the performance of the schedule which can be deceptive with time (Short, 1993) because of efficient distortion in predicting the schedule based on the schedule performance index (Lipke, 2004). The efficiency of the EVM method is based on how well the past work represents the efficiency of future work. Many researchers have been resulted based on the duration when cost performance index balances and can provide stable and final project estimate is forecasted (Fleming Q K. J., 2000). Anyway, results from other such observational studies have been dependent largely on constrained work test can barely be summed up to various activities, sizes and types (Payne, 1990). Cost performance index stability also based on the capability of project groups and the effective management systems, which alters over the duration (Zwikael, 2000). In addition to the research conclusion on cost performance index which can be uniformly applied to the stability of schedule performance index.

Estimate at Completion $($ EAC $)=$ Actual Cost of Work Performed (ACWP) + (Budget at Completion (BAC)

-Budgeted Cost for Work Performed (BCWP)

\begin{tabular}{|l|l|}
\hline Schedule Variance & SV=BCWP-BCWS \\
\hline Cost Variance & CV=BCWP-ACWP \\
\hline $\begin{array}{l}\text { Schedule Performance } \\
\text { Index }\end{array}$ & SPI=BCWP/BCWS \\
\hline Cost Performance Index & $\mathrm{CPI}=\mathrm{BCWP} / \mathrm{ACWP}$ \\
\hline$\%$ of Schedule Variance & $\% \mathrm{SV}=100 *(\mathrm{SV} / \mathrm{BCWP})$ \\
\hline $\begin{array}{l}\text { \% of Cost Variance } \\
\text { Total \% of complete }\end{array}$ & $=100 *(\mathrm{BCWP} / \mathrm{BAC})$ \\
\hline $\begin{array}{l}\text { Total Cost Performance } \\
\text { Index }\end{array}$ & $\begin{array}{l}\text { TCPI=(BAC-BCWP)/ (BAC- } \\
\mathrm{ACWP})\end{array}$ \\
\hline $\begin{array}{l}\text { Estimate Duration at } \\
\text { Completion }\end{array}$ & $\mathrm{Planned}$ Duration /SPI \\
\hline
\end{tabular}

\section{EXPONENTIAL SMOOTHING TECHNIQUE}

Even though the exponential smoothing procedures have been around since the 1950s, there has not been an inside and out made showing stochastic models, predictions of duration and determination of models. In this paper, we create an idea of filling the gap. Exponential smoothing is no doubt the by and a large used class of strategies for smoothing discrete time course of action to appraise the brief future (Brown, 1961). This unmistakable quality can be credited to its ease, its computational efficiency, the straightforwardness of adjusting its responsiveness to changes all the while and its reasonable accuracy Here, unmistakable compact inception of exponential smoothing procedure is conveyed. In studies, exponential smoothing systems are totally simple foreseeing techniques that have ended up being amazingly favored because of relative consistency and extraordinary as a rule execution by thinking about the examples, normality and substitute highlights of the required measurable information (Hyndman, 2002). In exponential smoothing methods, the straightforward moving midpoints are picked, here more weight is given for ongoing information than the past perceptions. The exponential capacities are utilized to allow exponentially decreasing loads over the period. Along these lines, here we close the prior information gives less effect to the expectation more than the more current one. Smoothing steady is chosen by the decline of loads of the prior information. More industry utilizes these methods for forecasting (Maia A. L., 2011) (Gardner, 2006). Here, a simple exponential technique is utilized for predicting the duration. The exponential smoothing examination uses the smoothing constant $\alpha$, the span of which chooses the measure of the past error to forecast. Smoothing constant $\alpha$ esteem lies somewhere in the range of 0 and 1, the higher esteem 1(Under smoothing), past qualities have no effect over-

anticipate, the lower esteem 0 (Over smoothing), past qualities have the same effect on foresee (Homayoun Khamooshi, 2016). In this forecasting technique, the forecasting value is derived as follows,

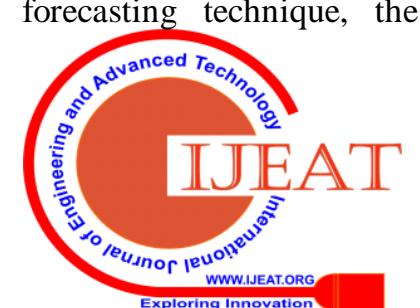


$\mathrm{Pt}=\alpha \mathrm{At}+\mathrm{Pt}-1(1-\alpha)$

where $\mathrm{Pt}$ is the prediction time for ' $\mathrm{t}$ '

$\alpha$ is the smoothing constant

At is the actual predicting time

Pt-1 is the previous predicting time Analysis of data

\section{SMOOTHING TECHNIQUE}

The completed projects of ROB and High-level Bridge (HLB) projects are taken and fed into the exponential smoothing technique by varying the $\alpha$ constants as $0.3,0.6$ and 0.9. The average duration of the project is 835.66667 days and the cost are 14.7925 crores (INR).

Table 1: Construction cost and duration of the project

\begin{tabular}{|c|c|c|c|c|c|}
\hline Project No. & Construction Cost & $\begin{array}{l}\text { Construction } \\
\text { duration (days) }\end{array}$ & 0.3 & 0.6 & 0.9 \\
\hline 1 & 20.94 & 1825 & 1825 & 1825 & 1825 \\
\hline 2 & 6.5 & 1095 & 1825 & 1825 & 1825 \\
\hline 3 & 4.1 & 2007.5 & 1606 & 1825 & 1825 \\
\hline 4 & 4.92 & 547.5 & 1726.45 & 1693.6 & 1825 \\
\hline 5 & 9.5 & 180 & 1372.76 & 1712.31 & 1706.74 \\
\hline 6 & 2.55 & 1095 & 1014.93 & 1508.98 & 1712.653 \\
\hline 7 & 28 & 540 & 1038.95 & 1212.55 & 1529.35 \\
\hline 8 & 4.2 & 365 & 889.26 & 1108.39 & 1244.2341 \\
\hline 9 & 39 & 910 & 731.98 & 976.91 & 1121.9786 \\
\hline 10 & 28.8 & 730 & 785.39 & 829.96 & 991.42489 \\
\hline 11 & 4 & 365 & 768.77 & 803.22 & 846.10675 \\
\hline 12 & 25 & 368 & 647.64 & 782.55 & 807.5078 \\
\hline
\end{tabular}

Table 2: List of activities and present status

\begin{tabular}{|c|c|c|c|c|}
\hline 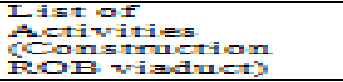 & ED=nmed & 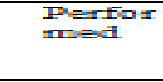 & $\begin{array}{l}\text { serned } \\
\square 1=\mathrm{d}\end{array}$ & $\Rightarrow 0=7$ \\
\hline 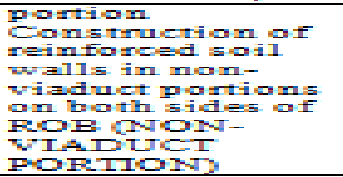 & $1 \geq 7000000$ & $100=$ & $100=-$ & $1=7000$ \\
\hline 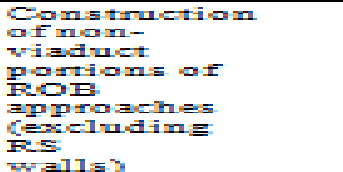 & $1 \mathrm{~B}=0 \mathrm{agat}$ & 1000 & $100=$ & I.: $=0$ avalo \\
\hline 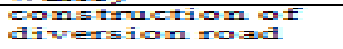 & 1. 1 a doua & 1.000 & $1000=$ & Ia liagua \\
\hline 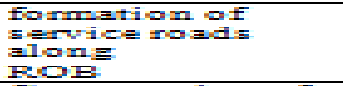 & 150000000 & $50=-$ & $00=-$ & $1=000000$ \\
\hline 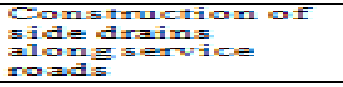 & $2=-9000000$ & 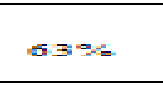 & $\operatorname{lag}=$ & $2=000000$ \\
\hline 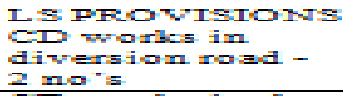 & $\exists=00000$ & $100=$ & $1000=$ & $\exists=0000$ \\
\hline 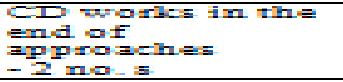 & Davouar & $5=0-$ & $\sec =$ & 960000 \\
\hline 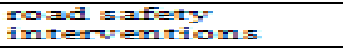 & 5000000 & $0=$ & $0=$ & Stavoura \\
\hline 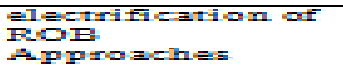 & 2500000 & 250 & $250=$ & 250000 \\
\hline 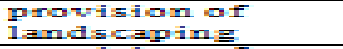 & 20000000 & $0=$ & $a=$ & $=\log 00$ \\
\hline 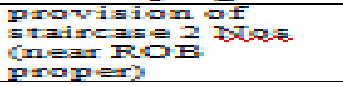 & 1.500000 & $55=$ & $55=$ & $1 \leq 0000$ \\
\hline 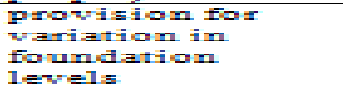 & 2000000 & $1000=$ & $1000=$ & 2000000 \\
\hline
\end{tabular}




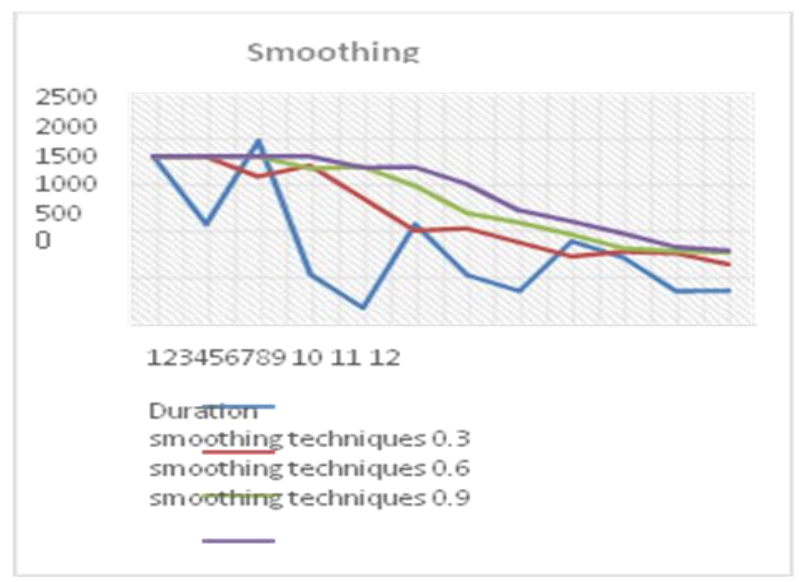

\section{Fig1: Different smoothing constant value for duration prediction}

As per the graph view, a comparison is made between the constant values. Smoothing constant 0.3 is given the gradually declining line when compared with 0.6 and 0.9 . This graph indicates 0.3 gives the markable impacts in the forecasting error.

\section{Comparison between EVM and Smoothing technique}

A comparison is made between Earned value management and exponential smoothing technique with the constants $(0.3,0.6$ and 0.9). Here the duration lies declining in exponential soothing techniques at $\alpha=0.3$

Hence, here we can conclude that the smoothing technique performs well more than earned value management.

Table3: MAPE comparison between smoothing techniques and EVM techniques

\begin{tabular}{|c|c|c|c|c|c|}
\hline \multirow{2}{*}{$\begin{array}{l}\text { Prediction } \\
\text { techniques }\end{array}$} & \multirow[t]{2}{*}{ Actual } & \multicolumn{3}{|c|}{ Smoothing techniques (\%) } & \multirow{2}{*}{$\begin{array}{l}\text { EVM } \\
\text { Techniques }\end{array}$} \\
\hline & & 0.3 & 0.6 & 0.9 & \\
\hline MAPE & 0 & 11.28 & 7.20 & 10.62 & 3.84 \\
\hline
\end{tabular}

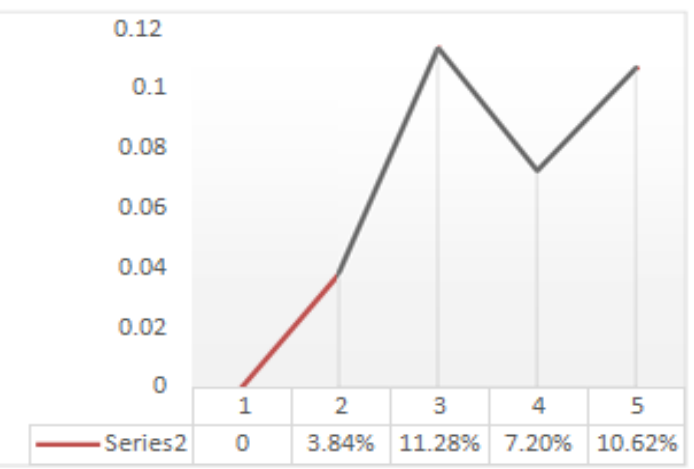

Fig 2: Comparison graph between Smoothing techniques and EVM techniques

From the above graph view, we concluded that MAPE error is minimal for EVM technique than all other techniques but also it is only possible for an ongoing project.

\section{RESULT AND DISCUSSION}

Before the sum up, all the above-mentioned factors should be considered, and the duration of the project is predicted. Also, the EVM technique is only suitable for ongoing projects, while the exponential smoothing technique can be used to predict both the completed and ongoing projects. As compared to the other prediction techniques, smoothing provides a competitive result with error margin below 10\%. But here, EVM produces a better result in duration prediction as it an ongoing government project. Prediction models are evaluated in detailed only for Indian Highway projects; the same practice could be followed to evaluate the other sectors also.

\section{CONCLUSION}

Predicting construction project duration for future with accurate efficiency by considering all the delay factors is a big challenge. In this way, it needs a reasonable way to deal with the present, lessen the time and cost overrun issue. This investigation examines the physical significance of PV, EV, and $\mathrm{AC}$, and their related fluctuations are defined in EVM. It is presented that, there are different measures of calculating workload, here in EVM technique cost is chosen as a measurement of project progress. It appears to be that work execution is equivalent to time execution. But once a project delays, then the work execution is not equivalent to the time of completion. Most often time delays are not considered as a big factor rather other factors also cause duration delays for a project. Here the time prediction is predicted using earned value management technique. There are also various methods are used for predicting the construction duration of an ongoing project.

\section{REFERENCES}

1. (PMI), P. M. (n.d.). A guide to the project management body of knowledge. 4th Ed., Newton Square, PA.

2. Abdi, H. K. (2016). Project Duration Forecasting using Earned Duration Management with Exponential Smoothing Techniques. J. Manage. Eng., 04016032.

3. Anbari, F. T. Earned value project management method and extensions project management, 34(4), 2003, 12-23

4. B.C. Kim, K. R. Probabilistic forecasting of project duration using the Kalman filter and the earned value method. J.Constr. Eng. Manage, 130(1) 2010, 25-32.

5. Brown, R. G. The fundamental theory of exponential smoothing. Opera. Res., 9(5), 1961, 673-685.

6. Christensen, D. The estimate at completion problem: A review of three studies. Proj, Manage. J., 24(1), 1993, 37-42.

7. Fleming Q K. J. Earned value project management new town square. PMI. Fleming Q, K. J. What's your project's real price tag? Harvard bus rev. 81(9): (2003), 20-1.

8. Gardner, E. S.Exponential smoothing: The state of the art. Part II. Int. J. Forecasting, 22(4),2006, 637-666

9. Homayoun Khamooshi, A. A. Project duration forecasting using earned duration management with exponential smoothing techniques. Journal of Management in Engineering, Vol. 33(1) 2016, Pages 04016032.

10. Hyndman, R. J. A state space framework for automatic forecasting using exponential smoothing methods. Int. J. Forecasting, 18(3), 2002, 439-454.

11. Koppelman, Q. W. (2000). Earned Value Project Management.

12. Maia, A. L. Holt's exponential smoothing and neural network models for forecasting interval-valued time series. Int. J. Forecasting, 27(3), 2011, 740-759.

13. Marco, T. N. (2013). Combination of Growth Model and Earned Schedule to Forecast Project Cost at Completion. J. Constr. Eng. Manage., 04013038.

14. Payne, K. (1990). An investigation of the stability of the cost performance index. MS Thesis, Air Force Institute of Technology, Wright-Patterson AFB, Ohio.

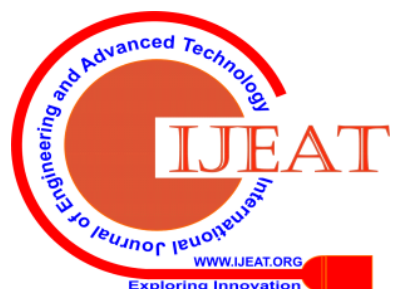


15. Reinschmidt, B.-C. K. (2010). Probabilistic Forecasting of Project Duration Using Kalman Filter and the Earned Value Method. J. Constr. Eng. Manage, Vol. 136 No. 8.

16. Rispoli, I. D. (2014). Case study Narrative in Teaching Construction Project Management: Earned Value Methods Examples. Pract. Period. Struct. Des. Constr., Vol. 19, No.1.

17. S. Vandevoorde, M. V. A comparison of different project forecasting methods using earned value metrics. Int. J. Proj. Manage, 2006, 289-302

18. Short, J. (1993). Using Schedule variance as the only measure of schedule performance. Cost Enf., 35(10), 1993, 35-40.

19. Vanhoucke, J. B. (2015). Empirical Evaluation of Earned Value Management Forecasting Accuracy for Time and Cost. J. Constr. Eng. Manage., 05015010-1.

20. Yu, C.-J. C.-W. (2018). Three-Variance Approach for Updating Earned Value Management. construction engineering and management, Vol. 144 Issue 6.

21. Zwikael, O. G. Evaluation of models for forecasting the final cost of a project. project. Manage. J., 31(1) 2000, 53-57.

\section{AUTHORS PROFILE}
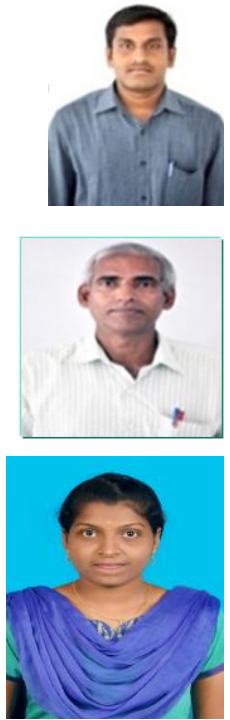

Velumani P, M. Tech (Construction Engineering and Management) Pursuing Ph. D in the fields of prediction profile, Published 6 Nos of international journals. Working as a Civil Engineering faculty since 2014 at Kalasalingam Academy of Research and Education, Krishnankoil, India.

Nampoothiri N, Ph. D, Published around 50+ no of International journals. Finished $\mathrm{Ph}$. $\mathrm{D}$ at Indian institute of Technology, Bombay. Recipient of workshop grant from NRDMS, DST

Aparna Devi M. Tech (Construction Engineering and Management) Published 2 Nos of international journals Studied at Kalasalingam Academy of Research and Education, Krishnankoil, India. 